\title{
Measuring urban economic resilience of two tropical cities, using impulse response analysis
}

\author{
Taha Chaiechi $^{1}$ and Trang Nguyen ${ }^{2}$
}

\begin{abstract}
The global urbanisation rate had increased rapidly from just $30 \%$ in 1950 to $55 \%$ in 2018 , and it is projected to reach $68 \%$ by 2050 . This ongoing urbanisation shows the importance of building resilient economies in dealing with complex external financial and public health shocks and disturbances. Although most growing cities are beginning to demonstrate dedication to integrating sustainable development goals, building economic resilience in cities remains a significant challenge. During the past crises, stronger economies have shown an apparent ability to recover from shocks relatively quickly. Nonetheless, the severe COVID-19 recession has unmasked superficial evidence of economic resilience while also identifying underlying vulnerabilities and economic weak-spots. Accordingly, this paper focuses on resilience as a non-equilibrium property of urban economic structures. Focusing on two tropical cities, the paper explores sources of volatility transmission as indicators of urbanisation change, by utilising orthogonal impulse- response (OIR) functions based upon the Cholesky decomposition. The findings suggest a metropolitan disadvantage concerning urban economic resilience predominantly from shocks on sources of urbanisation.
\end{abstract}

JEL classification numbers: P25, O4, Q56,

Keywords: economic resilience, urban economics, urbanisation, tropical cities, impulse response analysis

\section{Introduction}

The new millennium has witnessed widespread and frequent external shocks resulting in massive economic losses, depressions, and loss of lives. Noteworthy natural, financial, and public health crisis in the past 20 years include frequent large-scale natural disasters around the world on an annual basis, the bursting of the Dot-Com bubble in 2000-2002, SARS pandemic in 2002-2004, Global Financial Crisis (GFC) of 2008, MERS-CoV pandemic in 2012, European sovereign debt crisis (2009-2019), and COVID19 pandemic of 2020. These crises straddled broad geographic areas, adversely affected all economic sectors, hindered economic activities, and endangered lives and well-being worldwide. Although stronger economies have shown an apparent ability to recover from economic crises in the past relatively quickly, the severe COVID-19 recession has unmasked superficial evidence of economic resilience while also identifying underlying vulnerabilities and economic weak-spots.

\footnotetext{
${ }^{1} \mathrm{PhD}$, Associate Professor, College of Business, Law, and Governance, James Cook University, Australia

${ }^{2} \mathrm{PhD}$, Trade Development Officer, Trade and Business Development, Port of Townsville, Australia
} 
In addition to frequent health and financial crises, the global urbanisation rate had increased rapidly from just $30 \%$ in 1950 to $55 \%$ in 2018, and it is projected to reach $68 \%$ by 2050 (United Nations, 2018a). Mass movements of people to cities result from several defining factors, including economic factors (such as job opportunities and higher disposable incomes), lifestyle preferences, health, and education. Swift expansion of cities geographic extent and urban clustering has led to extensive land recycling in many areas to suit urban life, adversely impacting the natural environment, agricultural landscapes, and resource allocations. Continuous and evolving urbanisation that primarily results from rural to urban migration is changing city structures and is altering the structure of the broader economy.

North America is the most urbanised region in the world with $82 \%$ of its population living in urban areas, Latin America and the Caribbean comes in second place with 81\%, Europe and Oceania follow suit with $74 \%$, and $68 \%$ in that order. The more balanced regions include Asia, with almost 50\% urbanisation and Africa, with $43 \%$ of its population living in urban areas (United Nations, 2018b). This ongoing urbanisation shows the importance of building resilient economies in dealing with complex external financial and public health shocks and disturbances. And while most growing cities are beginning to demonstrate dedication to integrating sustainable development goals (Chaiechi, 2020a), building urban economic resilience remains a significant challenge.

However, the relationship is not that simple. Urban agglomeration may induce and facilitate some economic activities; it may also lead to diseconomies of scale as business clusters may contribute to pollution and other negative externalities. Diseconomies of scale resulting from urban agglomeration lead to strong environmental pressures, price distortions, and inequalities, consequently jeopardising urban areas' resilience against external shocks. The urban economic theory suggests that concentration benefits can be offset by increasing congestion, overcrowding, and pressure on the environment. These negative externalities intensify as cities expand, especially without careful planning for resilience and futureproofing.

Moreover, a large body of literature often portrays an entirely predictable relationship between urbanisation and economic growth. Many of these arguments are mainly broad-brush, and the supporting evidence is rather insufficient. More importantly, the concept of urban economic resilience is rarely discussed in the literature, and its methods of quantification are poorly understood. Accordingly, this paper's main point of departure is to offer measuring techniques to quantify urban economic resilience by moving beyond decontextualised and limited research around the concept of economic resilience.

In addition to the insufficient number of theoretical and empirical studies around the concept of economic resilience, regrettably, in many crisis scenarios, it has also become evident that policy-makers have resorted to short-term responses rather than adopting various approaches to building economic resilience, hugely compromising the purported rights of forthcoming generations.

This paper focuses on resilience (as competence) as a non-equilibrium property of urban economic structures. The authors explore the sources of volatility transmission as indicators of urbanisation change, allowing us to investigate the urban economic resilience of selected cities in the presence of external shocks. Accordingly, this study is designed to assess the hypothesis that changes in indicators of urbanisation influence economic growth volatility transmission. The paper introduces an orthogonal impulse- response (OIR) function based upon the Cholesky decomposition under which condition all shocks are expected to be transitory, either around a deterministic trend or around some unconditional 
mean. By calibrating the framework to time series quarterly data from 2001 to 2018, the paper finds the susceptibility of selected cities' economic growth to external shocks on urbanisation indicators.

\section{Literature review}

Non-equilibrium economics explains events' economic processes as a non-equilibrium phenomenon that stands against standard classical equilibrium economic theories. Most classical models focus on equilibrium conditions, and therefore, the concept of resilience does not naturally fit within classical theories. Integrating the concept of economic resilience into classical models would be challenging as it would provoke a paradigmatic change. However, frameworks and methods for out-of-equilibrium phenomena have been repeatedly presented in contemporary economic theories, including PostKeynesian economics and ecological economics. In this paper, without getting into these controversies, we focus on several seminal works that had helped improve the conceptual and theoretical understanding of economic resilience.

\subsection{Economic Resilience}

The concept of resilience has always been discussed in the United Nations Development agenda. For example, Hyogo Framework for Action 2005-2015 (United Nations, 2005) was first introduced in the World Conference on Disaster Reduction in Kobe, Japan, in 2005 - only days after the 2004 Indian Ocean Tsunami. Another crucial UN report called "Resilient People, Resilient Planet - A Future Worth Choosing" was published in 2012. This report contains 56 recommendations to put sustainable development into practice through inclusive economic growth, environmental development and social equity (United Nations Secretary-General's High-level Panel on Global Sustainability, 2012).

In academia, where there is an overall insufficient number of papers around resilience, several notable articles have discussed essential resilience dimensions in economic systems in details. Holling (1973) is one of the pioneers in the field who introduced resilience as a property of economic systems that determines the persistence of relationships within systems and is indicative of the ability of systems to absorb external shocks. Holling (1973) is indeed one of the early studies that attempted to invalidate the equilibrium-based economic theories put forward by classical economists. A couple of decades later, Mileti's Disaster by Design (1999) provided an alternative framework to view, investigate and manage environmental hazards to build disaster-resilience communities and economic sustainability. Mileti's work was well received amongst the researchers and policy-makers in the field of disaster and emergency management policy.

Until the early 2010s, research on disasters and resilience was dominated by physical scientists. There was a lack of social sciences' contributions to the concept of resilience. As Mileti (1999, P1) quoted, White and Haas (1975) attempted to fill this void by advancing the "critical notion that rather than simply picking up the pieces after disasters, the nation could employ better planning, land use controls, and other preventive and mitigatory measures to reduce the toll in the first place" (Mileti, 1999, P1).

Holling (1996) introduced "engineering resilience" that was particularly relevant in the field of material engineering and used as an indication for exemplary performance in tolerating stress and pressure. Socioecological systems (SES) were first proposed as a tool to measure resilience by Berkes et al. (2003). This work inspired other seminal studies such as Fischer et al. (2006), and Cabell and Oelofse, (2012) that led to the conceptualisation of "ecological resilience", a view built on the deliberation of the interaction 
between society and the environment through socio-ecological systems to build ecological resilience. Rose (2004) acknowledged three levels of difficulties (conceptual, operational, empirical) confronting researchers in the field of economic resilience, summarising progress in all three levels. Rose (2004) introduces two types of resilience: inherent resilience as an ability to operate under normal circumstances and adaptive resilience as the ability to remain functional during a crisis.

\subsection{Urbanisation and Economic Growth}

Historically, economic growth and urbanisation share a complex yet dynamic relationship tied to firms locations decisions (Alonso, 1964), infrastructure development (Bairoch, 1988), transport infrastructure (Harris \& Ullman, 1945; Floyd \& Allen, 2002), employment (Castells, 1977:237; Hoffmann et al., 2019), land rent and rural-urban wage disparity (Gale et al. 2005; Jiang et al.,2012; D'Costa \& Overman, 2014; Deng et al., 2010), and commuting distance to work (Angel and Blei, 2016; Kim and Choi, 2019).

While cities remain economic powerhouses of the countries, there seems to be a lack of research on achieving adaptive economic resilience in the cities. Cadena et al. (2012) argued that some cities might decline as most cities continue to evolve and grow. This is all dependent on how well cities are positioned to mitigate the adverse effects of shifting economic landscapes. Capello et al. (2015) examined cities' role as sources of regional resilience in Europe using a scenario approach and simulation exercise. The paper found that e cities with more value-added activities, higher quality production factors, and more prominent network clusters exhibit the highest economic resilience.

Rodríguez-Pose (2018) conducted a review of studies focusing on disparities between rural and urban areas in the EU and concluded that persistent poverty, economic inequality, and lack of economic opportunities are the driving forces behind declining areas. The paper recommended that territorial interventions should focus on large and dynamic cities and not on lagging regions, a view that is supportive of agglomeration. However, the study conducted by Dijkstra et al. (2015) argued that rate of urbanisation in large European cities relative to the rest of the country has stagnated or even reversed in many of the developed EU countries, a pattern that contradicts with urban growth of megacities elsewhere in the world. The study suggested that the polycentric urban structure in Europe favours a high number of small and medium-sized cities to megacities that could contribute to this negative trend. The study also found that improved access to services and technology (including broadband) across developed European countries might have improved smaller urban areas' appeal.

There are positive economic implications for urbanisation. For example, urbanisation increases investment in public infrastructure, and the public transport system becomes more efficient, allowing city dwellers to live closer to hospitals, recreational and educational facilities (White et al., 2019). Firms located in city centres provide better-paying jobs than jobs offered in regional areas (Sanderson et al., 2017). Also, firms tend to maximise social and technological connectivity benefits due to complex city structures (Sennet, 2002), resulting in knowledge generation and innovation. The process of gaining new knowledge leads to knowledge spillover to other firms located in or around city boundaries (Audretsch and Feldman 2004; Audretsch et al., 2015; Bakhtiari and Breunig, 2015), positively affecting workers productivity, inducing economic growth. 


\section{Geographic Scope of the study}

This paper focuses on two tropical cities. The primary reason for this selection is that Tropics is currently home to over $42 \%$ of the world's population (Harding et al., 2016), a rate estimated to reach more than $50 \%$ by 2050 (State of the Tropics, 2014). Accordingly, tropical cities are swiftly expanding as more populations are relocating to these cities. Besides, the State of Tropics report (2014) also demonstrated that the Tropics' economic growth outperformed the rest of the world. In particular, this paper focuses on the tropical city of Cairns, Australia, and the city-state of Singapore.

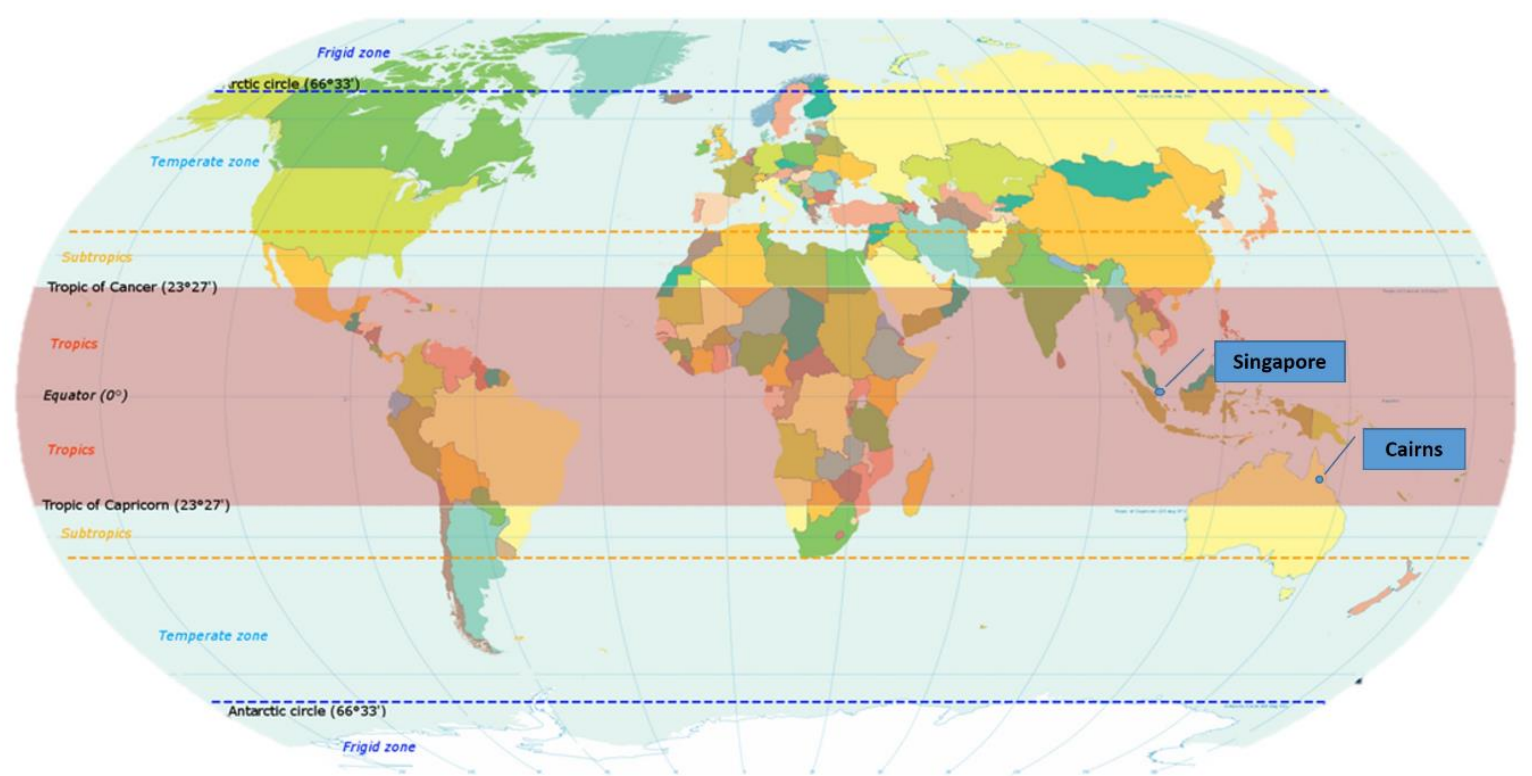

Figure 1: Tropics and Subtropics and the Locations of Two Selected Tropical Cities Source: adapted the map by KVDP based on World map torrid.svg (CC BY-SA 3.0)

Cairns is located in the Wet Tropics World Heritage Area in the eastern coastal tropics of Queensland. Cairns is a fast-growing city and is secluded from other major cities. Cairns' unique location means that the city needs local and state governments and town planners' attention to nurture constructive change to offer high-quality urban spaces and improve quality of life while providing economic opportunities. The city-state of Singapore is located near the equator. It has limited land and natural resources, with one of the highest urban population in Southeast Asia. Singapore's landscapes are continually evolving as urban planning and urban policies in Singapore guide modern Singapore's physical terrains. Despite Singapore being recognised as the most sustainable city in Asia and globally, it continues to face challenges given its land scarcity and rising population.

\section{Data, Data Sources, and Characteristics}

To investigate our selected cities' urban economic resilience, we follow Chaiechi (2020b), who modelled the urban economic growth process of two comparative case studies of Singapore and Cairns by constructing frameworks designed to illustrate complex the growth process identifying sets of relevant 
variables exclusive to each urban system. It is important to note that each city's choice of variables depends on the existing literature and data availability.

Accordingly, quarterly data on selected variables from 2001 to 2018 were retrieved from the Department of Statistics Singapore databases, Australian Bureau of Statistics, Cairns Regional Council and National Institute of Economic and Industry Research (NIEIR). All time-series data were adjusted for seasonality where appropriate to unveil the underlying base trends of the series. For the series of which only annual data are available, frequency conversion technique such as Quadratic Sum or Average Matched to the source were used to generate quarterly data from annual data. Table 1 presents two sets of indicators for urbanisation and economic growth in Singapore and Cairns (due to data availability).

Table 1: Set of Indicators for Urbanization and Economic Growth

\begin{tabular}{ll|ll}
\hline Singapore & & Cairns & \\
\hline Indicator & Notion & Indicator & Notion \\
\hline Gross Domestic Products (\$m) & GDP & Gross Regional Products (\$m) & GRP \\
Registered Businesses (units) & BIZ & Registered Businesses (units) & BIZ \\
Electricity Generation Output (Gwh) & ELG & Number of Local Jobs (jobs) & JOB \\
Employed Residents (people) & EMP & Employed Residents (people) & EMP \\
Health Facilities (units) & HFA & Urban Population (people) & POP \\
Residential Dwelling Units (units) & RDU & Value of Building Approvals (\$m) & BAP \\
Number of Teachers (\#) & TCH & Registered Motor Vehicles (units) & RMV \\
\hline
\end{tabular}

Note: * including all educational organisations such as primary, secondary, high schools, universities, etc.

Descriptive characteristics of all of the selected economic indicators for Singapore and Cairns cities are displayed in Table 2. Indicators with positive (negative) skewness imply that their distributions have thicker and longer right (left) tails than the Gaussian distribution. Most of the indicators showed kurtosis larger than 3, indicating the presence of leptokurtic distributions. Jarque-Bera statistics confirmed that most of the indicators are non-Gaussian distributed.

Table 2: Descriptive Statistics

\begin{tabular}{llllllll}
\hline \multicolumn{7}{c}{ Singapore } \\
\hline Mean & GDP & BIZ & ELG & EMP & HFA & RDU & TCH \\
Median & 0.015 & 0.009 & 0.007 & 0.005 & 0.010 & 0.005 & 0.007 \\
Maximum & 0.013 & 0.011 & 0.007 & 0.005 & 0.011 & 0.004 & 0.007 \\
Minimum & 0.061 & 0.202 & 0.040 & 0.045 & 0.072 & 0.012 & 0.030 \\
Std. Dev. & -0.071 & -0.393 & -0.029 & -0.018 & -0.018 & -0.001 & -0.021 \\
Skewness & 0.025 & 0.076 & 0.014 & 0.008 & 0.012 & 0.003 & 0.007 \\
Kurtosis & -0.748 & -1.962 & 0.101 & 1.080 & 1.830 & 0.311 & -0.432 \\
Jarque-Bera & 4.027 & 13.562 & 2.896 & 11.996 & 11.725 & 2.416 & 7.036 \\
& $9.881^{* * *}$ & $380.837^{* * *}$ & 0.155 & $256.782^{* * *}$ & $268.560^{* * *}$ & 2.183 & $51.109 * * *$ \\
& & \multicolumn{7}{c}{ Cairns } & & & \\
\hline Mean & GRP & BIZ & JOB & EMP & POP & BAP & RMV \\
Median & 0.009 & 0.004 & 0.007 & 0.006 & 0.005 & 0.010 & 0.009 \\
Maximum & 0.007 & 0.003 & 0.006 & 0.005 & 0.005 & 0.048 & 0.006 \\
Minimum & 0.037 & 0.022 & 0.025 & 0.021 & 0.012 & 0.402 & 0.029 \\
Std. Dev. & -0.011 & -0.008 & -0.010 & -0.010 & -0.001 & -0.485 & -0.003 \\
\hline
\end{tabular}




\begin{tabular}{llllllll}
\hline Skewness & 0.587 & 0.743 & 0.284 & 0.076 & 0.222 & -0.813 & 0.399 \\
Kurtosis & 3.483 & 5.054 & 3.024 & 3.196 & 1.859 & 5.042 & 2.437 \\
Jarque-Bera & $4.775 *$ & $19.017 * * *$ & 0.955 & 0.183 & 4.434 & $20.162 * * *$ & 2.819 \\
\hline
\end{tabular}

Notes: ***, * indicate the test statistic is significant at 1\% and 10\%; GDP denotes Gross Domestic Products; BIZ denotes the number of registered businesses; ELG denotes electricity generation output; EMP denotes the number of employed residents; HFA denotes the number of health facilities; RDU denotes residential dwelling units; TCH denotes the number of teachers in primary, secondary, high schools, universities, etc.; GRP denotes Gross Regional Products; JOB denotes the number of local jobs; POP denotes urban population; BAP denotes the value of building approvals; RMV denotes the number of registered motor vehicles.

\section{Analysis and Findings}

Consistent with this paper's main aim, which is to analyse and measure the urban economic resilience of two selected tropical cities, the paper adopts time series analysis techniques to develop impulse response functions offering a methodological advantage in interpreting results within a system approach. It is imperative to evaluate the times series' characteristics primarily. Accordingly, in this section, diagnostic tests such as stationarity, causality (block exogeneity), cointegration, and stability tests are conducted to avoid any model misspecification.

\subsection{Stationarity}

Testing for stationarity before further analysis is essential because regression of non-stationary variables may instigate accumulated shocks in the system of equations, leading to permanent effects. As such, all variables were tested for stationarity at level $I(0)$ and the first difference $I(1)$ using standard unit root tests developed by Augmented Dickey and Fuller (1981), Phillips and Perron (1988) and Ng and Perron (2001). The results are reported in Appendix A, showing that most of the variables in the case of Singapore were stationary in both orders of integration, $I(0)$ and $I(1)$, while all variables in the case of Cairns became stationary in the first order of integration $I(1)$. Therefore, all variables in both cases are used in their first differenced form before proceeding with subsequent analysis.

\subsection{Cointegration Test}

Since the endogenous variables for the cities of Singapore and Cairns, as determined in the previous section, were identified to be $I(1)$, the cointegration relationship might exist between the variables. To test for the presence of such a relationship, the Johansen (1991) cointegration rank test was adopted. This test estimates the maximum likelihood of the coefficient matrix of a VAR model to identify the number of cointegration equations, was adopted. The test results are reported in Table 3, showing three cointegration relationships among the endogenous variables in Cairns' case. At the same time, there is no cointegration presence among the variables in the case of Singapore. Therefore, a VAR model and a VEC model that incorporates an error correction term should be a good fit for Singapore and Cairns' data, respectively. 
Table 3: Identification of Johansen Cointegrating Equations

\begin{tabular}{lllll}
\hline & Singapore & Cairns & \\
\cline { 2 - 5 } & Trace Statistic & Max-Eigen Statistic & Trace Statistic & Max-Eigen Statistic \\
\hline No. of cointegrating & 0 & 0 & 3 & 3
\end{tabular}

equation(s)

Notes: Trace statistic and Max-eigenvalue statistic indicate the number of cointegrating equations at the 5\% level of significance.

\subsection{Block Exogeneity Wald Test}

Exogeneity is a critical issue when adopting a VAR/VEC model. It may cause the model to be too restrictive, which then misleads the system variables' dynamic interactions. Thus, the Block Exogeneity Wald test was conducted to examine what variables should be included or excluded in the final models. As presented in Table 4, the null hypothesis of exogeneity or non-causality was rejected for the economic growth indicator and some of the urbanisation indicators, indicating that these indicators are endogenous and exhibit causality. Notably, in Singapore's case, the determined endogenous indicators are GDP, the number of registered business, electricity generation output, and the number of teachers in all educational organisations. In Cairns' case, the determined endogenous indicators are GRP, urban population, the number of registered businesses, employed residents and registered motor vehicles. These variables are valid to be included in a VAR/ VEC system and later will be imposed shocks for an impulse response analysis.

Table 4: Block Exogeneity Wald Test

\begin{tabular}{lll|lll}
\hline Singapore & & & Cairns & & \\
\hline Indicator & Notation & Chi-sq (df=4) & Indicator & Notation & Chi-sq (df=4) \\
\hline Gross domestic products & GDP & $38.26^{* *}$ & Gross regional products & GRP & $30.85^{* *}$ \\
Registered businesses & BIZ & $40.39^{* *}$ & Registered businesses & BIZ & $28.70^{* *}$ \\
Electricity generation output & ELG & $48.65^{* * *}$ & Number of local jobs & JOB & 20.07 \\
Employed residents & EMP & 13.17 & Employed residents & EMP & $35.70^{* * *}$ \\
Health facilities & HFA & 21.02 & Urban population & POP & $26.18^{*}$ \\
Residential dwelling units & RDU & 18.72 & Residential building approvals & BAP & 19.17 \\
Number of teachers & TCH & $35.14^{*}$ & Registered motor vehicles & RMV & $34.09^{* * *}$ \\
\hline
\end{tabular}

Notes: $* * * * *, *$ indicate that Chi-squared statistic is significant at $1 \%, 5 \%$, and $10 \%$, respectively; df is the degree of freedom.

\subsection{Lag Length Selection}

An optimal lag length procedure was followed to avoid over-parameterisation in the system of equations and serial correlation in the residuals. Using an optimal lag length helps ensure the consistency and reliability of the model estimations and the precision of impulse response analysis. All variables in the system were regressed with the same lag order, which was identified by different statistical information criteria such as LR (sequentially modified likelihood ratio), FPE (Final Prediction Error), AIC (Akaike Information Criterion), SC (Schwarz Information Criterion), and HQ (Hannan-Quinn Information Criterion). As indicated in Table 5, three reports that lag 4 were chosen by three out of five criteria (LR, FPE and AIC) for both Singapore and Cairns cases. Accordingly, a VAR/VEC model with 
lag 4 was set up for both cases. The adoption of higher lags was not considered to avoid a further reduction in the already low degrees of freedom due to the lack of sufficiently long time-series data.

Table 5: Lag Length Selection

\begin{tabular}{ccccccc}
\hline Lag & LogL & LR & FPE & AIC & SC & HQ \\
\hline \multicolumn{7}{c}{ Singapore } \\
\hline 0 & $1,391.61$ & NA & $1.41 \mathrm{E}-27$ & -41.96 & $-41.73^{*}$ & $-41.87^{*}$ \\
1 & $1,438.81$ & 82.95 & $1.51 \mathrm{E}-27$ & -41.90 & -40.05 & -41.17 \\
2 & $1,477.27$ & 59.44 & $2.18 \mathrm{E}-27$ & -41.58 & -38.10 & -40.21 \\
3 & $1,538.71$ & 81.92 & $1.70 \mathrm{E}-27$ & -41.96 & -36.85 & -39.94 \\
4 & $1,667.03$ & $143.87^{*}$ & $2.00 \mathrm{E}-28^{*}$ & $-44.36^{*}$ & -37.63 & -41.70 \\
5 & $1,712.89$ & 41.69 & $3.55 \mathrm{E}-28$ & -44.27 & -35.91 & -40.97 \\
& \multicolumn{5}{c}{ Cairns } \\
0 & $1,928.56$ & NA & $4.95 \mathrm{E}-35$ & -59.13 & $-58.89^{*}$ & $-59.03^{*}$ \\
1 & $1,941.99$ & 23.55 & $1.49 \mathrm{E}-34$ & -58.03 & -56.16 & -57.29 \\
2 & $1,945.65$ & 5.62 & $6.34 \mathrm{E}-34$ & -56.64 & -53.12 & -55.25 \\
3 & $1,958.11$ & 16.49 & $2.23 \mathrm{E}-33$ & -55.51 & -50.36 & -53.48 \\
4 & $2,164.65$ & $228.79^{*}$ & $2.31 \mathrm{E}-35^{*}$ & $-60.36^{*}$ & -53.57 & -57.68 \\
5 & $2,178.34$ & 12.21 & $1.14 \mathrm{E}-34$ & -59.27 & -50.84 & -55.95 \\
\hline
\end{tabular}

Note: * indicates lag order selected by the criterion; LogL is log-likelihood; LR is sequentially modified likelihood ratio test statistic (each test at 5\% level); FPE is Final Prediction Error; AIC is Akaike Information Criterion; SC is

Schwarz Information Criterion; HQ is Hannan-Quinn Information Criterion.

\subsection{Post-Estimation Diagnosis and Stability Condition}

According to the block exogeneity test and cointegration rank test results, a VAR model and a VEC model were established for the identified set of endogenous variables for Singapore and Cairns (reported in Appendix B). To avoid model misspecification, serial correlation and heteroscedasticity tests in the residuals were conducted. As reported in Table 6, the residuals serial correlation Lagrange Multiplier test statistics were statistically insignificant in both cases, indicating zero autocorrelation in the model residuals up to lag 15. The White Heteroscedasticity joint test results show that the two models' residuals were homoscedastic and independent with the regressors.

Table 6: Residuals Diagnostics

\begin{tabular}{|c|c|c|c|c|}
\hline & Singapore & & Cairns & \\
\hline \multicolumn{5}{|c|}{ Residuals Serial Correlation Lagrange Multiplier Tests } \\
\hline Lag & Rao F-stat & P-value & Rao F-stat & P-value \\
\hline 1 & 1.44 & 0.13 & 0.18 & 0.96 \\
\hline 5 & 0.95 & 0.51 & 0.79 & 0.75 \\
\hline 10 & 1.09 & 0.38 & 0.17 & 0.98 \\
\hline 15 & 1.44 & 0.13 & 0.23 & 0.89 \\
\hline \multicolumn{5}{|c|}{ Residuals White Heteroscedasticity Tests (levels and squares) } \\
\hline Joint test: & Chi-sq & P-value & Chi-sq & P-value \\
\hline & 316.87 & 0.54 & 722.23 & 0.19 \\
\hline
\end{tabular}


As such, the VAR and VEC models adopted for each city are a good fit for the corresponding set of endogenous variables. Furthermore, the two models' stability condition is also ensured because the models' AR invert roots lied within the unit circle, as depicted in Figure 2.
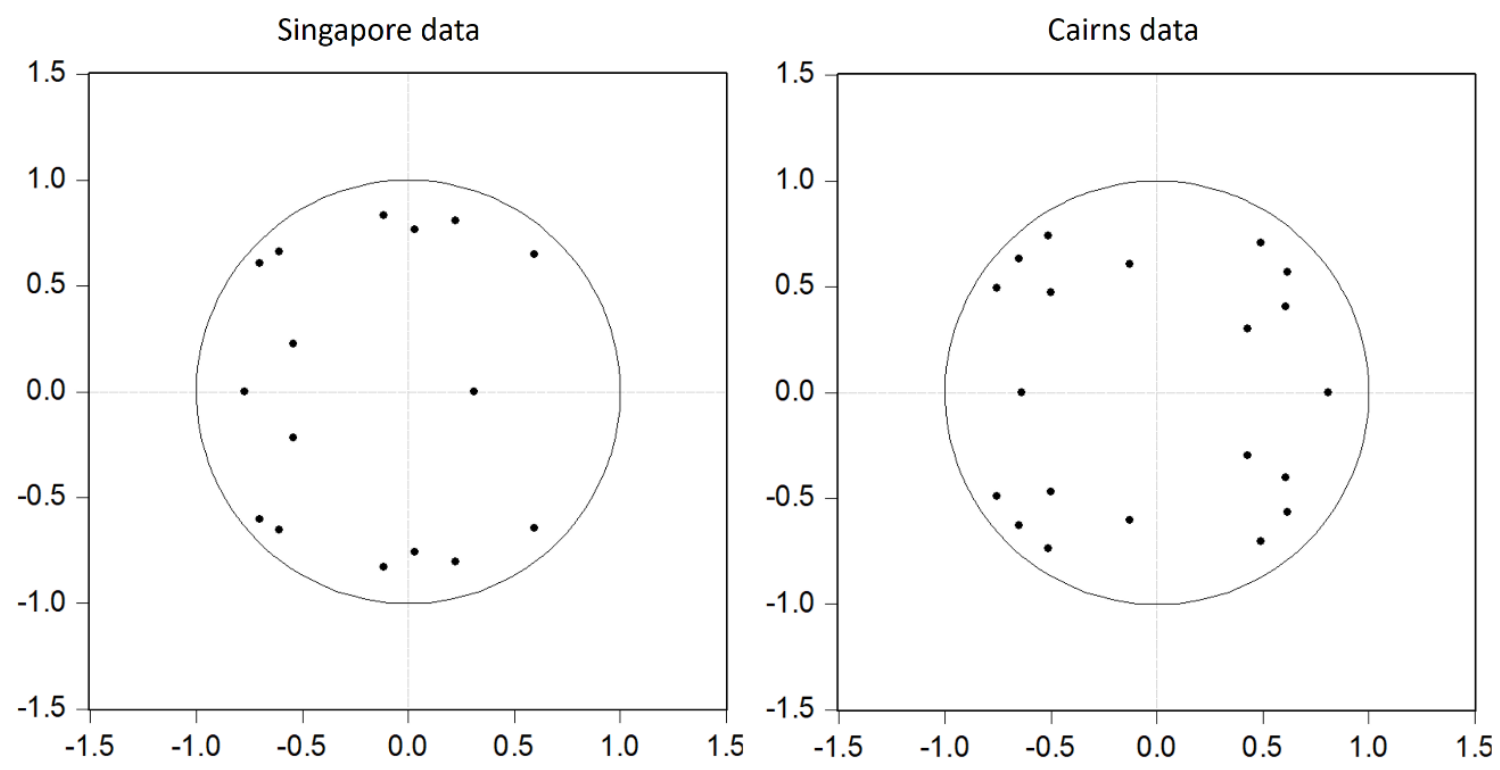

Figure 2: Stability Condition - Inverse Roots of AR Characteristic Polynomial

\subsection{Impulse Response Analysis}

This section investigates urban economic resilience by measuring the economic growth indicator's long impulse responses to simulated external shocks imposed on urbanisation indicators. Using this method comes with the added benefit of empirically investigating the absorbability and recoverability of these selected cities' economic systems. The recovery speed is measured by variance decomposition (demonstrated in section 5.7), which shows how much of the forecast error variance of the economic growth indicator is explained by exogenous shocks to urbanisation indicators.

The responses of cities' economic growth indicators to orthogonal shocks in urbanisation indicators are the main areas of interest in this section. Figures 3 and 4 depict urban economic growth's impulse responses to Cholesky one-standard-deviation shock on urbanisation sources over 30 quarters. The number of quarters before the response line crosses the zero baselines indicates the recovery speed after a shock, capturing these two tropical cities' relative economic resilience to external shocks.

According to the response patterns in figure 3, economic growth in Singapore was immediately influenced by the orthogonal shocks of one-standard-deviation change in the number of registered businesses and electricity generation output. Shocks in these urbanisation indicators resulted in a significant oscillation of economic growth along the baseline for a relatively long period (up to 20 quarters) before returning to pre-shock levels. Economic growth's response to a shock to the education 
system indicator was more short-lived and lasted around ten quarters. The overall results indicate that one-standard-deviation shock to any of these sectors would generate a long-lasting impact on the urban economy of the city-state of Singapore.

The response of GDP to BIZ

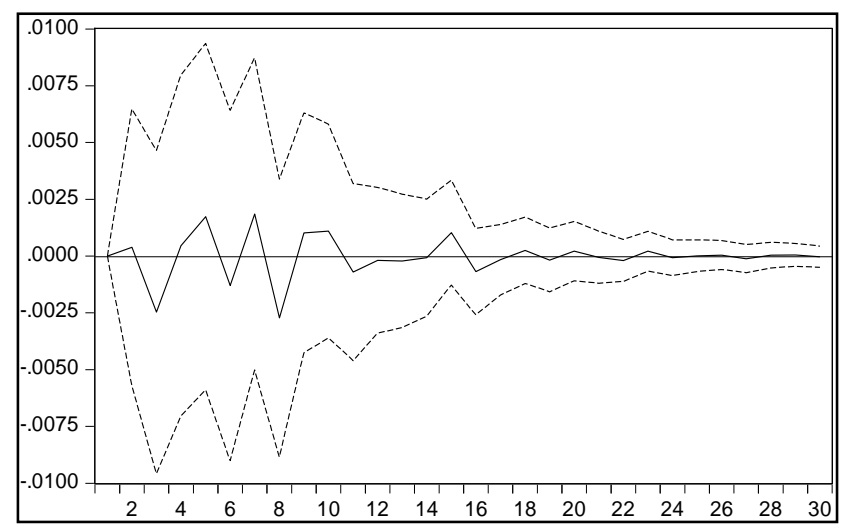

The response of GDP to ELG

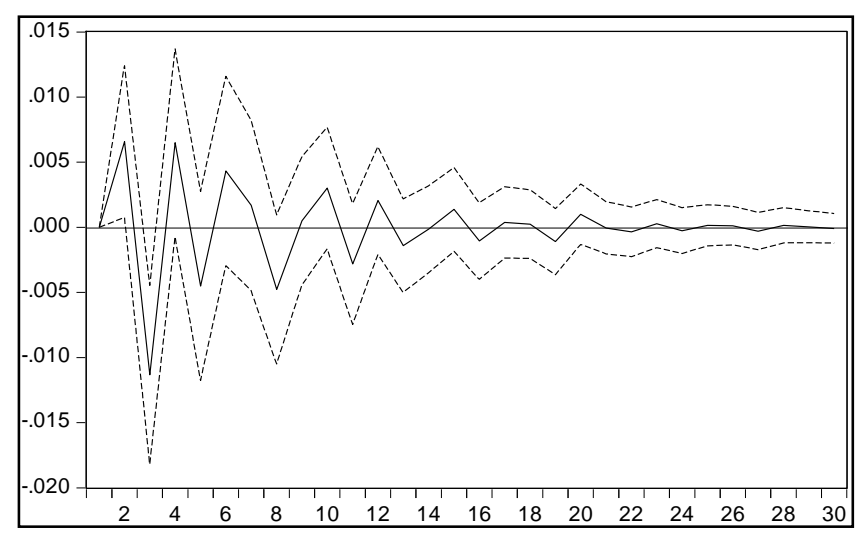

The response of GDP to TCH

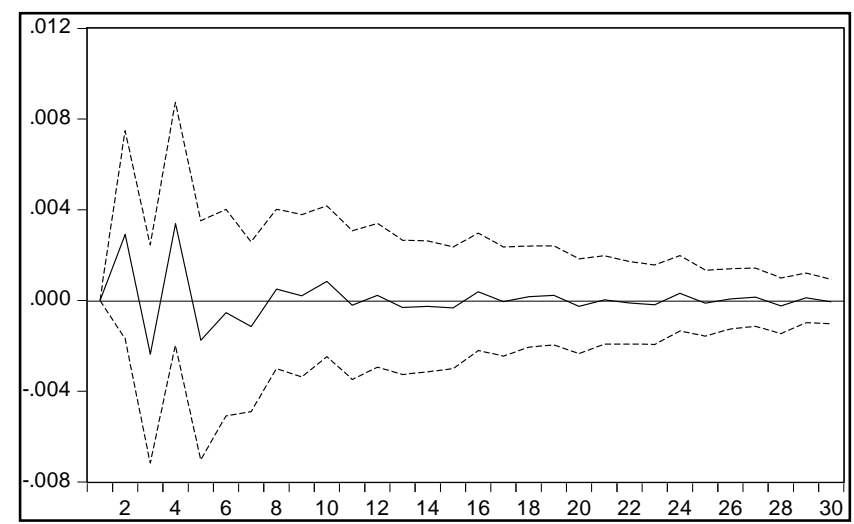

Figure 3: Impulse Response Analysis for Orthogonal Shocks to Urbanisation Indicators to Economic Growth in Singapore

Note: GDP denotes Gross Domestic Products; BIZ denotes the number of registered businesses; ELG denotes electricity generation output; TCH denotes the number of teachers in primary, secondary, high schools, universities, etc. 
Figure 4 demonstrates the Cairns model's impulse response simulation, delineating the city's economic response to a one-standard-deviation shock to the number of employed residents, registered businesses, registered motor vehicles, and urban population. Thus, unfolding the endogenous mechanism of urban economic turbulence and resilience.

The response of GRP to EMP

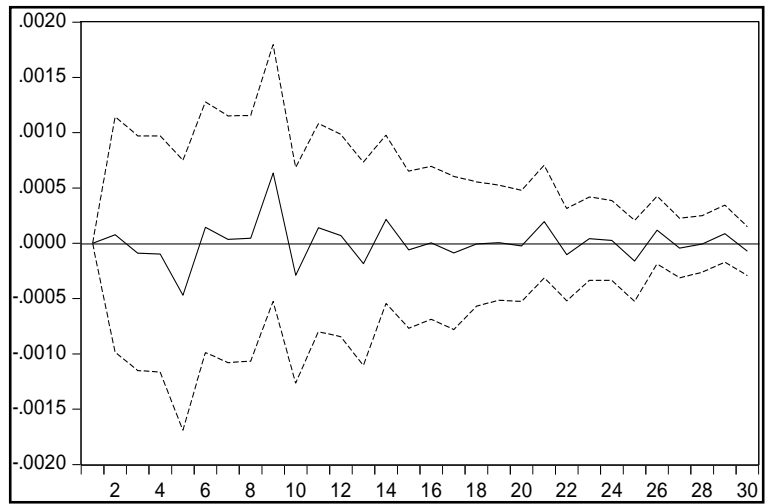

The response of GRP to POP

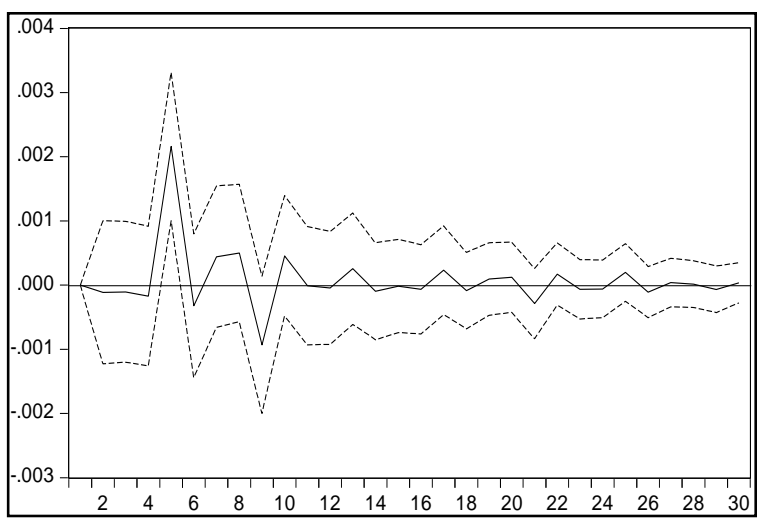

The response of GRP to BIZ

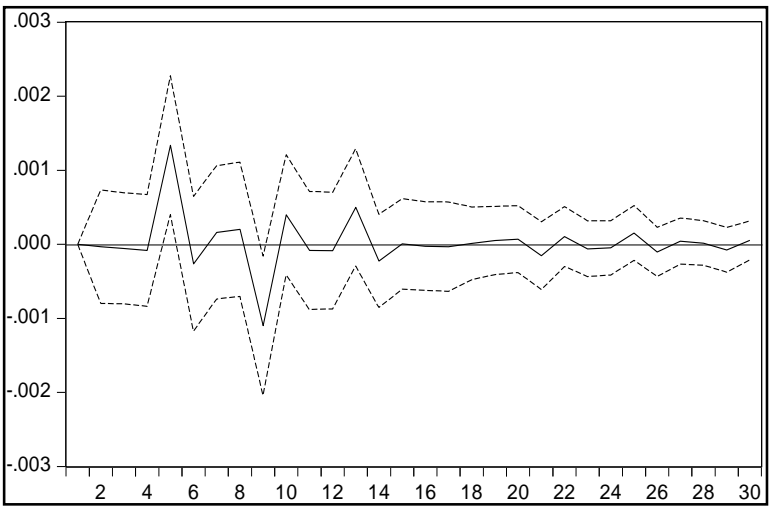

The response of GRP to RMV

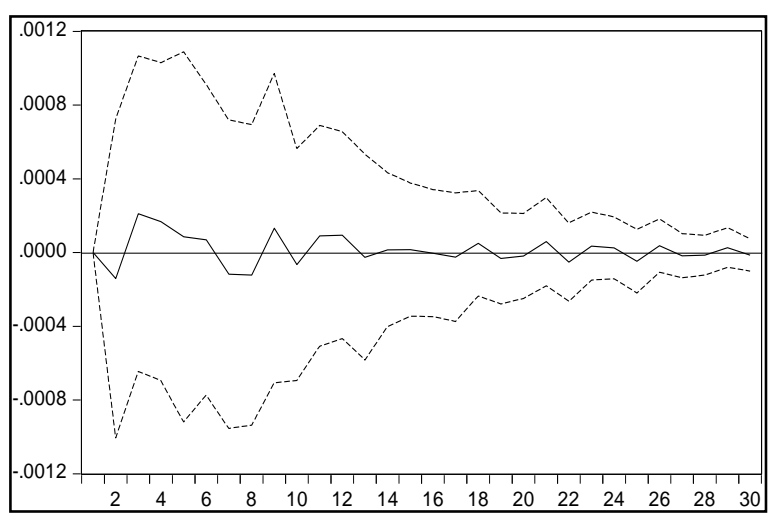

Figure 4: Impulse Response Analysis for Orthogonal Shocks to Urbanisation Indicators to Economic Growth in Cairns

Note: GDP denotes Gross Domestic Products; BIZ denotes the number of registered businesses; ELG denotes electricity generation output; TCH denotes the number of teachers in primary, secondary, high schools, universities, etc.; GRP denotes Gross Regional Products; EMP denotes the number of employed residents; RMV denotes the number of registered motor vehicles, and POP denotes urban population.

The simulation results of the urbanisation changes in Cairns economic resilience indicate that the city economy would be susceptible to unpredicted shock from employment, number of registered businesses, number of registered motor vehicles and the city's population. However, the economic instability caused by urbanisation shocks seems to be shorter-lived in Cairns than in Singapore as the impacts tend to weaken and dissipate after 12-14 quarters in the Cairns to 20 quarters in Singapore economy. The finding implies that the Cairns economy is more resilient to shocks arisen from urbanisation than Singapore economy. The result of Singapore's impulse response analysis is not surprising; there have been recent reports explaining while Singapore's economy is in good shape, it may not progressing quickly enough to allow economic growth to adjust to domestic and external shocks swiftly (Bhaskaran,2018). Some of the 
challenges that may be slowing down Singapore's economy include ageing demographics, housing affordability, re-structuring the education sector for better relevance ${ }^{3}$. From the data point of view, as observed in Table 2, Singapore's GDP exhibits a significantly higher standard deviation (0.025) than that of Cairns' GRP (0.009), indicating Singapore's GDP is much more volatile compared to Cairns' GRP. Thus, when facing an external shock, Singapore's economy tends to be more volatile than the Cairns economy.

\subsection{Variance decomposition}

We use Cholesky variance decomposition, proposed by Sims (1980), as an identification scheme that creates a recursive contemporaneous ordering amongst the variables, meaning that variables do not depend contemporaneously on the variables that are ordered after. The idea is to measure the recovery or adjustment speed (as an essential aspect of resilience) amongst urbanisation indicators after "orthogonal" uncorrelated shocks. Drawing on our time series data, we utilised Sim's Cholesky decomposition technique to measure our model variables' compositional speed adjustments in response to simulated shocks. Results are shown in table 7 and 8 . The table columns give the forecast variance percentage due to orthogonal shocks, decomposing the total variance of those time series indicators into the percentages attributable to each shock. Each row adds up to 100.

Results of variance decomposition of urbanisation indicators in Singapore is reported in Table 7. The results provide information about the relative importance of urbanisation indicators affecting urban economic growth. Findings indicate that compositional adjustment in economic growth indicator has been partial and limited, becoming stronger only when there is a shock to electricity generation output (ELG). In particular, the results reveal that only after five periods, the fluctuation in ELG itself explained 72.76\% of its total variance, whereas the GDP accounted for $18.58 \%$. This indicates that in our Singapore model, the energy sector and economic growth are strongly interconnected, and external shocks in energy production will influence the stability of the city's economic growth.

Table 7: Variance Decomposition of Urbanisation Indicators- Singapore

\begin{tabular}{ccccc|cccc|cccc}
\hline \multicolumn{1}{c}{ Variance Decomposition of BIZ } & \multicolumn{3}{c}{ Variance Decomposition of ELG } & \multicolumn{3}{c}{ Variance Decomposition of TCH } \\
\hline Period & GDP & BIZ & ELG & TCH & GDP & BIZ & ELG & TCH & GDP & BIZ & ELG & TCH \\
\hline 1 & 2.10 & 97.90 & - & - & 7.15 & 0.31 & 92.54 & - & 0.97 & 2.73 & 0.55 & 95.75 \\
2 & 4.74 & 91.83 & 1.64 & 1.79 & 11.09 & 1.31 & 87.57 & 0.03 & 4.91 & 5.08 & 2.24 & 87.77 \\
3 & 4.95 & 86.75 & 6.25 & 2.04 & 17.33 & 5.27 & 75.56 & 1.84 & 5.06 & 5.78 & 2.80 & 86.36 \\
4 & 4.99 & 86.09 & 6.67 & 2.25 & 17.43 & 6.43 & 74.25 & 1.89 & 5.11 & 6.15 & 3.37 & 85.37 \\
5 & 5.50 & 82.51 & 6.73 & 5.27 & 18.58 & 6.25 & 72.76 & 2.40 & 5.03 & 4.39 & 2.65 & 87.93 \\
6 & 5.28 & 78.34 & 10.84 & 5.55 & 17.53 & 6.45 & 72.29 & 3.73 & 8.62 & 4.30 & 4.02 & 83.06 \\
7 & 6.98 & 76.68 & 10.95 & 5.39 & 17.51 & 6.56 & 72.13 & 3.80 & 8.81 & 4.31 & 4.06 & 82.83 \\
8 & 6.80 & 74.48 & 13.47 & 5.25 & 17.01 & 6.97 & 72.04 & 3.97 & 8.60 & 4.48 & 6.01 & 80.92 \\
9 & 7.48 & 72.50 & 14.45 & 5.57 & 16.75 & 7.39 & 71.59 & 4.27 & 7.70 & 4.26 & 7.00 & 81.04 \\
10 & 7.52 & 72.34 & 14.43 & 5.71 & 16.67 & 7.35 & 71.00 & 4.98 & 7.76 & 4.18 & 8.36 & 79.70 \\
\hline
\end{tabular}

Note: Cholesky Ordering: GDP BIZ ELG TCH; GDP denotes Gross Domestic Products; BIZ denotes the number of registered businesses; ELG denotes electricity generation output; TCH denotes the number of teachers in primary, secondary, high schools, universities, etc.

\footnotetext{
${ }^{3}$ https://thediplomat.com/2020/01/what-are-singapores-domestic-priorities-for-2020/
} 
Table 8 reports the result of the variance decomposition of urbanisation indicators in Cairns. We find economic dynamism components, with sizeable adjustments in gross regional products (GRP) following external shocks to the number of employed residents (EMP) and the number of registered businesses (BIZ). Results of Table 8 reveal that only after five periods, the fluctuation in EMP itself explained only $55.49 \%$ of its total variance, whereas the GRP and urban population (POP) accounted for $15.87 \%$ and $25.09 \%$, respectively. Similarly, BIZ's fluctuation explained only $39.14 \%$ of its total variance, whereas the GRP accounted for $48.62 \%$.

Table 8: Variance Decomposition of Urbanisation Indicators- Cairns

\begin{tabular}{|c|c|c|c|c|c|c|c|c|c|c|}
\hline \multicolumn{6}{|c|}{ Variance Decomposition of EMP: } & \multicolumn{5}{|c|}{ Variance Decomposition of BIZ: } \\
\hline Period & GRP & EMP & $\mathrm{BIZ}$ & RMV & POP & GRP & EMP & $\mathrm{BIZ}$ & RMV & POP \\
\hline 1 & 17.70 & 82.30 & - & - & - & 33.82 & 4.83 & 61.35 & - & - \\
\hline 2 & 17.02 & 82.32 & 0.46 & 0.20 & 0.00 & 32.67 & 5.81 & 61.34 & 0.17 & 0.01 \\
\hline 3 & 17.32 & 81.73 & 0.52 & 0.43 & 0.00 & 33.29 & 5.74 & 60.41 & 0.53 & 0.03 \\
\hline 4 & 18.12 & 80.62 & 0.53 & 0.73 & 0.01 & 34.67 & 5.61 & 58.77 & 0.92 & 0.04 \\
\hline 5 & 15.87 & 55.49 & 3.05 & 0.50 & 25.09 & 48.62 & 8.10 & 39.14 & 0.91 & 3.22 \\
\hline 6 & 16.14 & 54.99 & 3.30 & 0.92 & 24.65 & 48.87 & 8.02 & 38.05 & 1.92 & 3.15 \\
\hline 7 & 15.87 & 54.05 & 3.31 & 0.93 & 25.84 & 48.82 & 7.97 & 37.77 & 2.09 & 3.35 \\
\hline 8 & 15.54 & 52.81 & 3.34 & 0.92 & 27.39 & 48.87 & 7.88 & 37.32 & 2.18 & 3.74 \\
\hline 9 & 14.77 & 52.92 & 4.98 & 1.13 & 26.19 & 47.08 & 11.59 & 30.15 & 1.91 & 9.27 \\
\hline 10 & 14.38 & 51.13 & 5.31 & 1.24 & 27.94 & 46.72 & 11.45 & 29.80 & 2.39 & 9.65 \\
\hline \multicolumn{6}{|c|}{ Variance Decomposition of RMV: } & \multicolumn{5}{|c|}{ Variance Decomposition of POP: } \\
\hline Period & GRP & EMP & $\mathrm{BIZ}$ & RMV & POP & GRP & EMP & $\mathrm{BIZ}$ & RMV & POP \\
\hline 1 & 0.54 & 24.62 & 14.31 & 60.53 & - & 4.86 & 0.21 & 0.42 & 45.42 & 49.08 \\
\hline 2 & 0.53 & 25.03 & 14.16 & 60.05 & 0.23 & 4.83 & 0.32 & 0.76 & 45.34 & 48.75 \\
\hline 3 & 0.59 & 25.06 & 14.00 & 59.75 & 0.59 & 5.61 & 0.54 & 0.72 & 43.50 & 49.63 \\
\hline 4 & 0.95 & 24.77 & 13.79 & 59.19 & 1.29 & 6.50 & 0.61 & 0.67 & 41.33 & 50.90 \\
\hline 5 & 1.61 & 22.25 & 25.93 & 39.64 & 10.58 & 16.89 & 3.50 & 6.01 & 31.16 & 42.43 \\
\hline 6 & 2.09 & 21.82 & 25.44 & 39.61 & 11.04 & 17.07 & 3.30 & 5.79 & 29.65 & 44.20 \\
\hline 7 & 2.20 & 21.81 & 25.30 & 39.26 & 11.43 & 18.12 & 3.30 & 5.70 & 29.75 & 43.13 \\
\hline 8 & 2.49 & 21.71 & 25.15 & 38.89 & 11.76 & 20.02 & 3.26 & 5.56 & 29.61 & 41.55 \\
\hline 9 & 6.87 & 20.29 & 27.12 & 35.30 & 10.42 & 18.77 & 3.65 & 7.29 & 26.75 & 43.56 \\
\hline 10 & 6.96 & 20.18 & 27.10 & 34.79 & 10.98 & 20.27 & 3.82 & 7.35 & 26.80 & 41.76 \\
\hline
\end{tabular}

Note: Cholesky Ordering: GRP EMP BIZ RMV POP; GRP denotes Gross Regional Products; EMP denotes the number of employed residents; BIZ denotes the number of registered businesses; RMV denotes the number of registered motor vehicles, and POP denotes urban population.

This result confirms that both residents' employment and the number of registered urban businesses contribute the most to the Cairns' economic growth variance despite their relatively small size in the overall Cairns portfolio.

While impulse response analysis traces the effects of urbanisation indicators shocks on our selected cities' economic growth within a VAR system, variance decomposition analysis helped separate urbanisation indicators' variation into the component shocks to the VAR model. Impulse response analysis indicated that simulated shocks resulted in a significant oscillation of economic growth with a long-lasting impact 
on Singapore's urban economy. However, the economic instability caused by simulated shocks is predicted to be shorter-lived in Cairns, implying that Cairns' economy is more resilient to external shocks arisen from urbanisation than Singapore's economy. The variance decomposition results reveal further details about the relative importance of these simulated shocks in affecting sources of urban economic growth of our cities. The share of forecast-error variance attributable to urbanisation indicators in Singapore amounts to $7 \%-17 \%$ up to 10 years compared to their own innovation $(71 \%-79 \%)$. The compositional adjustment in cairns' data indicates a shock to one urbanisation indicator records an increasing impact on other urbanisation indicators, ranging between 9\%-40\% ahead of their own innovation (29\%-82\%). The results indicate that while variance decomposition evolves over time, urbanisation indicators in Cairns are stronger in explaining other variables' variability over time than Singapore.

\section{Conclusion}

While cities are the nation's economic powerhouses, they are subjected continuously to frequent unforeseen large-scale external shocks, including natural, financial, and public health disasters. These disasters swiftly agitate economic activity levels, potentially leading to social and economic instabilities. The detrimental effects of such disasters are far from being local as urban economies are intricately interconnected, spreading the shocks quickly across regions and countries. Respectively, this outlook sets out the importance of building and quantifying economic resilience.

Even though there have been limited advances in understanding economic resilience, the way resilience is measured remains in its infancy phase. More importantly, the concept of urban economic resilience is rarely discussed, and the concept is hardly quantified in the exiting literature. Accordingly, this paper's main point of departure is to offer methodology and techniques for measuring urban economic resilience that moves beyond decontextualised and limited research around the concept of urban economic resilience. While the existing literature suggests that strong relationships amongst any systems' elements improve resilience, this paper provides a novel approach in measuring urban economic resilience by determining contemporaneous feedback effects, absorbability, and recoverability of urban systems against external shocks (i.e. impulse response analysis). Moreover, the paper provides the added benefit of empirically capturing dynamic interaction amongst the urban economic model variables by indicating the amount of information each variable contributes to the other variables within the system (i.e. variance decomposition analysis).

Subsequently, this paper posits that urban economic growth determinants remain sensitive to changes/shocks to sources of urbanisation sources. The paper further postulates that urban economic resilience must be established at different levels to absorb these shocks and recover from detrimental effects relatively quickly. So from a novel perspective, this paper measures recoverability and speed of adjustment (as central aspects of resilience), using two tropical cities of Singapore and Cairns as case studies.

By relying on times series quarterly data and utilising advanced econometrics techniques including impulse-response analysis and decomposition techniques, this paper identified not only how external shocks to sources of urbanisation affected the economic resilience of two selected cities, but also, and perhaps more crucially, how much of the forecast error variance of urban economic growth rate is explained by exogenous shocks to urbanisation variables. This paper's findings suggest a metropolitan 
disadvantage concerning urban economic resilience predominantly from shocks on sources of urbanisation. Nonetheless, the results call for further analysis to explore how these cities counterbalance urbanisation's adverse effects. Furthermore, this study faced a number of limitations. Firstly, there was a limitation at the regional and urban level with available data. Secondly, this study did not consider spatial urban economic inequality as different urban areas may deal with external shocks differently across urban spaces. Given the outlook for the future of swiftly expanding tropical cities, it is imperative to ask what would be the other source of urban economic resilience in the future.

Finally, evidence-based policy-making (as opposed to ideology-based policy-making) is becoming more widely recognised and appreciated by governments worldwide. The need for systems to be informed by evidence at each stage of policy development is also becoming more acknowledged at government levels. Accordingly, the knowledge and evidence-based information provided in this paper should assist policymakers, city governments, and planners in designing a responsive and effective urban economy by truly understanding channels through which the sources of resilience are affected. Furthermore, this paper's results around shock absorbability and recoverability of urban economies should provide policy-makers with opportunities to make city economies more resilient, particularly when dealing with complex problems such as natural disasters and public health emergencies.

\section{References}

Alonso, W. (1964). Location and land use. Toward a general theory of land rent. Location and land use. Toward a general theory of land rent.Harvard Univesity Press.

Angel, S., \& Blei, A. M. (2016). The productivity of American cities: How densification, relocation, and greater mobility sustain the productive advantage of larger US metropolitan labor markets. Cities, 51, 36-51.

Audretsch, D., Feldman, M.P., (2004). Knowledge spillovers and the geography of innovation. Chapter 61 in Handbook of Regional and Urban Economics, 2004, vol. 4, pp 2713-2739. Elsevier

Audretsch, D., Heger, D., Veith, T., (2015). Infrastructure and entrepreneurship. Small Business Economics, 2015, vol. 44, issue 2, 219-230

Bairoch, P. 1988. Cities and Economic Development. Chicago: University of Chicago Press.

Bakhtiari, S. Productivity, outsourcing and exit: the case of Australian manufacturing. Small Bus Econ 44, 425-447 (2015). https://doi.org/10.1007/s11187-014-9604-2

Bhaskaran, M. (2018). Getting Singapore In Shape: Economic Challenges And How To Meet Them. The Lowy Institute. URL: https://www.lowyinstitute.org/publications/getting-singapore-shapeeconomic-challenges-and-how-meet-them-0

Berkes, F., Colding, J., Folke, C. (2003). Navigating Social-Ecological Systems: Building Resilience for Complexity and Change. Cambridge University Press.

Cabell, J. F., Oelofse, M. (2012). An Indicator Framework for Assessing Agroecosystem Resilience. Ecology and Society 17 (1).

Cadena, A., Dobbs, R., \& Remes, J. (2012). The Growing Economic Power of Cities. Journal of International Affairs, 65 (2) 1-XV

Capello, R., Caragliu, A., \& Fratesi, U. (2015). Spatial heterogeneity in the costs of the economic crisis in Europe: Are cities sources of regional resilience? Journal of Economic Geography, 15(5), 951-972. https://doi:10.1093/jeg/lbu053

Castells, M. (1977) The urban question. A Marxist approach. Translated from French by A. Sheridan. Edward Arnold, London. 
Chaiechi, T. (2020a). Sustainable Tropical Cities: A Scoping Review of Multidisciplinary Methods for Urban Planning. eTropic: Electronic Journal of Studies in the Tropics, 19(2), 25-51. https://doi.org/10.25120/etropic.19.2.2020.3743

Chaiechi, T., Wong, C., \& Tavares, S. (2020b). Urban Design and Economic Growth: An Analytical Tale of Two Tropical Cities. eTropic: Electronic Journal of Studies in the Tropics, 19(2), 172-200. https://doi.org/10.25120/etropic.19.2.2020.3741

D' Costa, S., Overman, H. G., 2014. The urban wage growth premium: Sorting or learning? Regional Science and Urban Economics 48, 168-179

Deng, X. , Huang, J. , Rozelle, S. , and Uchida, E. (2010). Economic growth and the expansion of urban land in China. Urban Studies, 47(4), 813-843.

Dickey, D., \& Fuller, W. (1981). Likelihood ratio statistics for autoregressive time series with a unit root. Econometrica: Journal of the Econometric Society, 49(4), 1057-1072.

Dijkstra, L., Garcilazo, E., \& McCann, P. (2015). The effects of the global financial crisis on European regions and cities. Journal of Economic Geography, 15, 935-949. doi:10.1093/jeg/lbv032

Fischer, J., Lindenmayer, D. B., Manning, A. D. (2006). Biodiversity, ecosystem function, and resilience: ten guiding principles for commodity production landscapes. Frontiers in Ecology and the Environment 4 (2), 80-86.

Floyd, C. F., \& Allen, M. T. (2002). Real estate principles. Dearborn Real Estate.

Gale H, Lohmar B, Tuan F (2005) China's new farm subsidies. Social Science Electronic Publishing (4). Washington, D.C., SDA-ERS WRS-05-01

Harding, S., Bird, G., Losos, E., Aderolili, R., \& Hotez, P. (2016). International Day of the Tropics: Towards a better global future. eTropic: electronic journal of studies in the tropics 15 (2), 5--12. https://doi.org/10.25120/etropic.15.2.2016.353

Harris, C. D., \& Ullman, E. L. (1945). The nature of cities. The Annals of the American Academy of Political and Social Science, 242(1), 7-17.

Hoffmann, E. M., Konerding, V., Nautiyal, S., \& Buerkert, A. (2019). Is the push-pull paradigm useful to explain rural-urban migration? A case study in Uttarakhand, India. PloS one, 14(4), e0214511. https://doi.org/10.1371/journal.pone.0214511

Holling, C.S. (1973). Excerpt from "Resilience and stability of ecological systems." Annual Review of Ecology and Systematics 4:1-23. The Future of Nature: Documents of Global Change, edited by Libby Robin et al., Yale University Press, 2013.

Holling, C. S. (1996). Engineering resilience versus ecological resilience. In: Schulze, P.(Ed.), Engineering Within Ecological Constraints. National Academies Press, pp. 31-44.

Jiang, L. , Deng, X. , and Seto, K. C. (2012). Multi-level modelling of urban expansion and cultivated land conversion for urban hotspot counties in China. Landscape and Urban Planning, 108(2-4), 131-139.

Johansen, S. (1991). Estimation and hypothesis testing of cointegration vectors in Gaussian vector autoregressive models. Econometrica: Journal of the Econometric Society, 59(6), 1551-1580.

Kim, C., Choi, C., (2019). Towards Sustainable Urban Spatial Structure: Does Decentralization Reduce Commuting Times? Sustainability 2019, 11(4), 1012. https://doi.org/10.3390/su11041012

Ng, S., \& Perron, P. (2001). Lag length selection and the construction of unit root tests with good size and power. Econometrica, 69(6), 1519-1554.

Mileti, DS, (1999). Disasters by Design: A Reassessment of Natural Hazards in the United States. Joseph Henry Press. Washington DC Natural Hazards Research and Applications Information

Phillips, P. C., \& Perron, P. (1988). Testing for a unit root in time series regression. Biometrika, 75(2), 335-346.

Rodríguez-Pose, A. (2018). The revenge of the places that don't matter (and what to do about it). Cambridge Journal of Regions, Economy and Society, 11(1), 189-209. https://doi:10.1093/cjres/rsx024

Rose, A. (2004), "Defining and measuring economic resilience to disasters", Disaster Prevention and Management, 13(4), pp. 307-314. https://doi.org/10.1108/09653560410556528 
Sanderson, T., Reeson, A., \& Mason, C. (2017). There's a huge disparity in skilled jobs in our cities and regions - and it is growing. The ABC News Online. Last viewed January 2021, https://www.abc.net.au/news/2017-12-13/australias-growing-skills-gap-cities-vs-regions-theconversation/9254740

Sennett, R. (2002). Cosmopolitanism and the social experience of cities. In S. Vertovec and R. Cohen (eds.), Conceiving cosmopolitanism: theory, context, and practice, OUP, Oxford.

Sims, C.A., (1980). Macroeconomics and Reality. Econometrica, 48, pp. 1-48

State of the Tropics (2014). State of the Tropics Report. James Cook University. http://stateofthetropics.org/the--report

United Nations (2005). Hyogo Framework for Action 2005-2015: Building the Resilience of Nations and Communities to Disasters. World Conference on Disaster Reduction. 18-22 January 2005, Kobe, Hyogo, Japan

United Nations Secretary-General's High-level Panel on Global Sustainability (2012). Resilient People, Resilient Planet: A future worth choosing. New York: United Nations.

United Nations (2018a). Department of Economic and Social Affairs, Population Division Revision of world urbanisation prospects 2018. https://population.un.org/wup/

United Nations (2018b). World Urbanization Prospects: The 2018 Revision. https://population.un.org/wup/Publications/Files/WUP2018--KeyFacts.pdf

White M.P., Grellier, J., Wheeler, B.W., Hartig, T., Warber, A.L., (2019). Spending at least 120 minutes a week in nature is associated with good health and well-being. Scientific Reports 9(1):7730.

White, G.F. and Haas, J.E. (1975). Assessment of Research on Natural Hazards. The Massachusetts Institute of Technology Press. Cambridge, Massachusetts. 
Appendix A: Unit Root Tests

\begin{tabular}{|c|c|c|c|c|c|c|c|c|c|c|c|c|c|c|}
\hline Singapore & GDP & $\mathrm{BIZ}$ & ELG & EMP & HFA & RDU & $\mathrm{TCH}$ & GDP & $\mathrm{BIZ}$ & ELG & EMP & HFA & $\mathrm{RDU}$ & $\mathrm{TCH}$ \\
\hline & \multicolumn{7}{|c|}{ Level $0[\mathrm{I}(0)]$} & \multicolumn{7}{|c|}{ Level 1 [I(1)] } \\
\hline \multicolumn{15}{|l|}{ ADF } \\
\hline $\mathrm{C}$ & $-7.00 * * *$ & $-8.93 * * *$ & $-8.71 * * *$ & $-4.03 * * *$ & -2.24 & -1.29 & $-3.70 * * *$ & $-8.12 * * *$ & $-7.66 * * *$ & $-7.28 * * *$ & $-8.55 * * *$ & $-8.18 * * *$ & $-5.60 * * *$ & $-7.32 * * *$ \\
\hline $\mathrm{C} \& \mathrm{~T}$ & $-6.95 * * *$ & $-7.83 * * *$ & $-8.76 * * *$ & $-4.26 * * *$ & -2.22 & -2.41 & $-3.67 * *$ & $-8.16^{* * *}$ & $-7.60 * * *$ & $-7.22 * * *$ & $-8.49 * * *$ & $-8.12 * * *$ & $-5.56 * * *$ & $-3.81 * *$ \\
\hline \multicolumn{15}{|l|}{$\mathrm{PP}$} \\
\hline $\mathrm{C}$ & $-6.95 * * *$ & $-13.74 * * *$ & $-8.92 * * *$ & $-5.61 * * *$ & $-4.20 * * *$ & -2.04 & $-5.44 * * *$ & $-26.65 * * *$ & $-37.84 * * *$ & $-35.03 * * *$ & $-12.04 * * *$ & $-12.32 * * *$ & $-181.66 * * *$ & $-11.29 * * *$ \\
\hline $\mathrm{C} \& \mathrm{~T}$ & $-6.88 * * *$ & $-19.96 * * *$ & $-9.29 * * *$ & $-5.58 * * *$ & $-4.18 * * *$ & -3.03 & $-5.44 * * *$ & $-30.44 * * *$ & $-37.89 * * *$ & $-34.81 * * *$ & $-11.80 * * *$ & $-12.21 * * *$ & $-83.43 * * *$ & $-11.22 * * *$ \\
\hline$M Z_{a}^{d}$ & $-12.39 * *$ & $-69.82 * * *$ & $-32.63 * * *$ & $-22.88 * * *$ & $-8.61 * *$ & -3.56 & $-10.62 * *$ & $-61.02 * * *$ & $-30.45 * * *$ & $-59.04 * * *$ & $-22.43 * * *$ & $-18.79 * * *$ & $-34.04 * * *$ & $-28.63 * * *$ \\
\hline$M Z_{t}^{d}$ & $-2.47 * *$ & $-5.91 * * *$ & $-4.03 * * *$ & $-3.37 * * *$ & $-2.03 * *$ & -1.33 & $-2.28 * *$ & $-5.52 * * *$ & $-3.90 * * *$ & $-5.43 * * *$ & $-3.35 * * *$ & $-3.06 * * *$ & $-4.13 * * *$ & $-3.78 * * *$ \\
\hline$M S B^{d}$ & $0.20 * *$ & $0.08 * * *$ & $0.12 * * *$ & $0.15^{* * *}$ & $0.24 * *$ & 0.37 & $0.21 * *$ & $0.09 * * *$ & $0.13 * * *$ & $0.09 * * *$ & $0.15^{* * *}$ & $0.16^{* * *}$ & $0.12 * * *$ & $0.13 * * *$ \\
\hline \multicolumn{14}{|l|}{ NP - C\&T } & $0.87 * * *$ \\
\hline$M Z_{a}^{d}$ & $-20.82 * *$ & $-71.37 * * *$ & $-34.99 * * *$ & $-30.14 * * *$ & -8.82 & -4.94 & $-28.01 * * *$ & $-6,835.17 * * *$ & $-512.10 * * *$ & $-70.27 * * *$ & $-24.03 * * *$ & $-18.84 * *$ & $-35.09 * * *$ & $-30.93 * * *$ \\
\hline$M Z_{t}^{d}$ & $-3.21 * *$ & $-5.97 * * *$ & $-4.18 * * *$ & $-3.88 * * *$ & -2.08 & -1.56 & $-3.71 * * *$ & $-58.46 * * *$ & $-16.00 * * *$ & $-5.92 * * *$ & $-3.47 * * *$ & $-3.07 * *$ & $-4.18 * * *$ & $-3.93 * * *$ \\
\hline$M S B^{d}$ & $0.15^{* *}$ & $0.08 * * *$ & $0.12 * * *$ & $0.13 * * *$ & 0.24 & 0.32 & $0.13 * * *$ & $0.01 * * *$ & $0.03 * * *$ & $0.08 * * *$ & $0.14 * * *$ & $0.16^{* *}$ & $0.12 * * *$ & $0.13 * * *$ \\
\hline \multirow[t]{2}{*}{ Cairns } & GRP & $\mathrm{BIZ}$ & JOB & EMP & POP & BAP & RMV & GRP & $\mathrm{BIZ}$ & JOB & EMP & POP & BAP & RMV \\
\hline & \multicolumn{7}{|c|}{ Level $0[\mathrm{I}(0)]$} & \multicolumn{7}{|c|}{ Level $1[\mathrm{I}(1)]$} \\
\hline \multicolumn{15}{|l|}{ ADF } \\
\hline $\mathrm{C}$ & -1.54 & -1.63 & -1.09 & -1.48 & -1.06 & -1.47 & -0.87 & $-5.15 * * *$ & $-5.16 * * *$ & $-5.48 * * *$ & $-6.19 * * *$ & $-4.46 * * *$ & $-4.87 * * *$ & $-4.11 * * *$ \\
\hline C\&T & -1.70 & -0.75 & -0.64 & -1.11 & $-3.23 *$ & -1.81 & -2.28 & $-5.12 * * *$ & $-5.37 * * *$ & $-5.63 * * *$ & $-6.27 * * *$ & $-4.63 * * *$ & $-4.91 * * *$ & $-4.07 * *$ \\
\hline \multicolumn{15}{|l|}{ PP } \\
\hline $\mathrm{C}$ & -2.14 & $-3.25 * *$ & -2.18 & $-2.87 *$ & -1.63 & $-4.15 * * *$ & -1.97 & $-10.35 * * *$ & $-10.91 * * *$ & $-10.61 * * *$ & $-10.70 * * *$ & $-9.75 * * *$ & $-10.66 * * *$ & $-10.90 * * *$ \\
\hline $\mathrm{C} \& \mathrm{~T}$ & -2.43 & $-3.81 * *$ & -1.96 & -2.74 & $-3.20 *$ & $-4.31 * * *$ & $-4.05 * *$ & $-10.28 * * *$ & $-10.89 * * *$ & $-10.71 * * *$ & $-10.74 * * *$ & $-10.00 * * *$ & $-10.62 * * *$ & $-10.82 * * *$ \\
\hline \multicolumn{15}{|l|}{$\mathrm{NP}-\mathrm{C}$} \\
\hline$M Z_{a}^{d}$ & $-8.37 * *$ & -1.23 & -4.69 & -4.63 & -2.03 & -2.76 & -0.37 & $-32.55^{* * *}$ & $-31.28 * * *$ & $-32.21 * * *$ & $-31.49 * * *$ & $-34.35 * * *$ & $-50.06 * * *$ & $-31.41 * * *$ \\
\hline$M Z_{t}^{d}$ & $-2.04 * *$ & -0.78 & -1.30 & -1.41 & -1.00 & -0.70 & -0.18 & $-4.03 * * *$ & $-3.95 * * *$ & $-4.00 * * *$ & $-3.96 * * *$ & $-4.14 * * *$ & $-4.97 * * *$ & $-3.96 * * *$ \\
\hline$M S B^{d}$ & $0.24 * *$ & 0.64 & 0.28 & 0.31 & 0.49 & 0.25 & 0.49 & $0.12 * * *$ & $0.13 * * *$ & $0.12 * * *$ & $0.13 * * *$ & $0.12 * * *$ & $0.10 * * *$ & $0.13 * * *$ \\
\hline$M P_{T}^{d}$ & $2.93 * *$ & 19.87 & 5.69 & 5.52 & 11.97 & 7.60 & 17.24 & $0.75^{* * *}$ & $0.79 * * *$ & $0.79 * * *$ & $0.81 * * *$ & $0.73 * * *$ & $0.56 * * *$ & $0.78 * * *$ \\
\hline \multicolumn{15}{|l|}{ NP - C\&T } \\
\hline$M Z_{a}^{d}$ & -10.64 & -2.71 & -5.10 & -6.39 & -4.05 & -6.07 & -18.80 & $-32.46 * * *$ & $-31.14 * * *$ & $-31.90 * * *$ & $-31.67 * * *$ & $-35.32 * * *$ & $-51.63 * * *$ & $-31.41 * * *$ \\
\hline$M Z_{t}^{d}$ & -2.28 & -0.93 & -1.32 & -1.55 & -1.39 & -1.51 & -3.06 & $-4.03 * * *$ & $-3.94 * * *$ & $-3.99 * * *$ & $-3.98 * * *$ & $-4.20 * * *$ & $-5.06 * * *$ & $-3.96 * * *$ \\
\hline
\end{tabular}

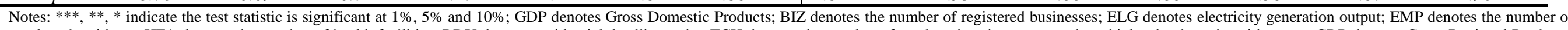

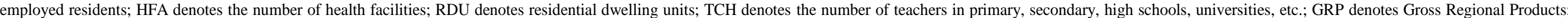
JOB denotes the number of local jobs; POP denotes urban population; BAP denotes the value of building approvals; RMV denotes the number of registered motor vehicles. 


\section{Appendix B:}

VAR Estimation Result - Singapore

\begin{tabular}{lrrrr}
\hline & DGDP & DBIZ & DELG & DTCH \\
\hline DGDP(-1) & $-0.53 * * *$ & $-0.56^{*}$ & $0.34 * * *$ & $-0.04 *$ \\
DGDP(-2) & $-0.50 * * *$ & -0.55 & $0.31 * * *$ & -0.02 \\
DGDP(-3) & -0.20 & -0.16 & $0.20 * *$ & -0.05 \\
DGDP(-4) & $0.23 *$ & -0.14 & $0.17 * *$ & $-0.09 * * *$ \\
DBIZ(-1) & 0.00 & $-1.03 * * *$ & 0.02 & -0.01 \\
DBIZ(-2) & -0.03 & $-1.05 * * *$ & -0.03 & $-0.02 * *$ \\
DBIZ(-3) & -0.01 & $-0.80 * * *$ & -0.01 & $-0.02 * *$ \\
DBIZ(-4) & -0.03 & $-0.36 * * *$ & $-0.04 * *$ & 0.00 \\
DELG(-1) & $0.53 * * *$ & $1.19 * *$ & $-0.90 * * *$ & $-0.06 *$ \\
DELG(-2) & -0.11 & 0.81 & $-1.05 * * *$ & 0.00 \\
DELG(-3) & 0.26 & 0.60 & $-0.49 * * *$ & 0.02 \\
DELG(-4) & $-0.37 *$ & $-1.02 *$ & $-0.53 * * *$ & 0.01 \\
DTCH(-1) & $0.56 *$ & $2.86 * *$ & -0.06 & $-0.19 * *$ \\
DTCH(-2) & -0.03 & $2.57 * *$ & 0.21 & 0.08 \\
DTCH(-3) & 0.46 & $2.62 * *$ & $0.38 *$ & 0.05 \\
DTCH(-4) & 0.15 & -1.54 & $0.53 * *$ & $-0.62 * * *$ \\
\hline R-squared & 0.78 & 0.89 & 0.87 & 0.87 \\
Adj. R-squared & 0.70 & 0.79 & 0.78 & 0.77 \\
F-statistic & 4.68 & 7.43 & 7.00 & 6.86 \\
Log likelihood & 165.89 & 86.70 & 202.98 & 264.88 \\
Akaike AIC & -4.47 & -2.11 & -5.58 & -7.43 \\
Schwarz SC & -3.95 & -1.58 & -5.06 & -6.90 \\
\hline
\end{tabular}

Notes: $* * *, * *, *$ indicate the test statistic is significant at 1\%,5\% and 10\%; GDP denotes Gross Domestic Products; BIZ denotes the number of registered businesses; ELG denotes electricity generation output; TCH denotes the number of teachers in primary, secondary, high schools, universities, etc.

VECM Estimation Result - Cairns

\begin{tabular}{lrrrrr}
\hline Cointegrating Eq: & CointEq1 & CointEq2 & CointEq3 & & \\
\hline DGRPSA(-1) & 1 & 0 & 0 & & \\
DEMPSA(-1) & 0 & 1 & 0 & & \\
DRBIZSA(-1) & 0 & 0 & 1 & & \\
DRMVSA(-1) & $-0.61 *$ & $1.09 * * *$ & 0.06 & & \\
DPOPSA(-1) & $-2.67 * * *$ & $-1.87 * *$ & -0.17 & & \\
C & 0.00 & 0.00 & 0.00 & & \\
Error Correction: & D(DGRP) & D(DEMP) & D(DRBIZ) & D(DRMV) & D(DPOP) \\
\hline CointEq1 & $-0.76^{* * *}$ & $-0.49 * *$ & -0.06 & $0.74 * * *$ & $0.18^{* * *}$ \\
CointEq2 & -0.35 & $-1.11^{* * *}$ & -0.15 & $-0.54 * *$ & 0.07 \\
CointEq3 & 0.16 & $0.82^{*}$ & $-1.48 * * *$ & $-0.92^{* *}$ & -0.19 \\
D(DGRP(-1)) & -0.19 & $0.48^{*}$ & 0.09 & $-0.76^{* * *}$ & $-0.18^{* *}$ \\
D(DGRP(-2)) & 0.18 & $0.55^{*}$ & 0.18 & $-0.78^{* * *}$ & $-0.19 *$ \\
D(DGRP(-3)) & $0.65 *$ & $0.67 *$ & 0.30 & $-0.76^{* * *}$ & $-0.20^{* *}$ \\
D(DGRP(-4)) & -0.26 & -0.09 & -0.13 & -0.12 & 0.01 \\
D(DEMP(-1)) & 0.30 & -0.03 & 0.23 & $0.54 * *$ & -0.08 \\
D(DEMP(-2)) & 0.10 & -0.05 & 0.21 & $0.58^{* *}$ & -0.04 \\
\hline
\end{tabular}




\begin{tabular}{lrrrrr}
\hline D(DEMP(-3)) & -0.16 & -0.06 & 0.17 & $0.63 * * *$ & 0.01 \\
D(DEMP(-4)) & 0.17 & 0.05 & 0.08 & 0.08 & -0.02 \\
D(DRBIZ(-1)) & -0.25 & $-0.66^{*}$ & 0.32 & $0.94 * * *$ & 0.17 \\
D(DRBIZ(-2)) & -0.48 & $-0.69 *$ & 0.27 & $0.95 * * *$ & $0.18^{*}$ \\
D(DRBIZ(-3)) & $-0.75^{*}$ & $-0.78^{* *}$ & 0.23 & $0.94 * * *$ & $0.21^{* *}$ \\
D(DRBIZ(-4)) & 0.19 & -0.01 & 0.19 & 0.12 & 0.00 \\
D(DRMV(-1)) & -0.04 & $0.78^{* *}$ & 0.18 & -0.15 & 0.02 \\
D(DRMV(-2)) & 0.23 & $0.83 * *$ & 0.22 & -0.20 & -0.04 \\
D(DRMV(-3)) & 0.57 & $0.94 * *$ & 0.29 & -0.21 & -0.10 \\
D(DRMV(-4)) & -0.20 & -0.01 & -0.09 & 0.01 & 0.05 \\
D(DPOP(-1)) & $-2.74 * *$ & $-3.21 * * *$ & -0.72 & $1.01 *$ & $-0.41 *$ \\
D(DPOP(-2)) & $-2.82^{* *}$ & $-3.17 * * *$ & -0.67 & $1.29 *$ & -0.12 \\
D(DPOP(-3)) & $-2.99 * *$ & $-3.20 * * *$ & -0.60 & $1.63 * *$ & 0.22 \\
D(DPOP(-4)) & 0.13 & -0.12 & 0.24 & 0.00 & -0.19 \\
C & 0.00 & 0.00 & 0.00 & 0.00 & 0.00 \\
\hline R-squared & 0.78 & 0.84 & 0.86 & 0.84 & 0.74 \\
Adj. R-squared & 0.70 & 0.74 & 0.78 & 0.76 & 0.69 \\
F-statistic & 6.30 & 9.07 & 10.71 & 9.66 & 5.19 \\
Log likelihood & 273.82 & 291.06 & 307.74 & 302.97 & 366.55 \\
Akaike AIC & -7.69 & -8.22 & -8.73 & -8.58 & -10.54 \\
Schwarz SC & -6.88 & -7.41 & -7.93 & -7.78 & -9.74 \\
\hline (D)
\end{tabular}

Notes: $* * * * *, *$ indicate the test statistic is significant at $1 \%, 5 \%$ and $10 \%$; GRP denotes Gross Regional Products; RBIZ denotes the number of registered businesses; EMP denotes the number of employed residents; POP denotes urban population; RMV denotes the number of registered motor vehicles. 